\title{
Insurance Pricing and Anti-Discrimination Legislation
}

\author{
Alan E. Woodfield
}

$\mathbf{M}$ any countries have legislation seeking to prevent discrimination. Outlawed practices typically include those based on highly visible characteristics of individuals such as sex, age or race, but sometimes include less visible characteristics, such as religion or sexual preference.

Should insurance companies be required in law to offer insurance under the same terms and conditions to people irrespective of their sex? This article tries to answer this question by reference to the outcomes of such legislation. It should be noted at the outset that although insurance firms charge women more than men for some types of insurance (such as annuity purchases and disability insurance), insurers also charge men more than women for other types of insurance (such as life and vehicle-collision insurance). These sex-based differences in insurance premiums reflect cost differences, arising from sex-related differences in risk.

The article concludes that unisex insurance pricing creates adverse selection in insurance markets and is inefficient. Unisex insurance pricing is an ineffective device for raising the welfare of those who pay high premiums because of their sexbased high risk. Not only may it fail to raise their welfare, but targeted tax-subsidy policies are more efficient. These conclusions are relevant also where categorisation is based on other sources of risk difference, such as age or race.

\section{Sources of Discrimination}

At face value, charging some people a higher price because of their sex appears to be discriminatory. Discrimination, however, can mean many different things. It may reflect prejudice, resulting in different people being charged different prices for what is the same commodity. Discrimination may also result from the exercise of monopoly power. However, what may appear to be price discrimination often turns out to involve price differences that are based on genuine differences in costs.

Discrimination based on prejudice is very difficult to sustain in competitive markets; and it is hard to argue that insurance markets are not highly competitive. They are characterised by the presence of many firms, relatively few barriers to entry (although they must attract sufficient numbers of customers to permit efficient risk-pooling), and relatively low profits. They appear to attract little attention from anti-monopoly commissions. Even if insurers wanted to act prejudicially towards 
one or other sex (and it is quite unclear why they would wish to do), their ability to do so would be removed by the presence of other firms who were not prejudiced, and who would undercut the discriminating firms.

A similar argument applies to monopolistic price discrimination. Suppose that risk did not differ by sex, and an insurer tried to make excess profits, say, by charging a higher premium per dollar of cover to women than to men. Even though men would be unable to resell their low-priced insurance contracts to women, competitors would undercut the premium for women and gain all their custom. With a sufficient level of competition, there would be one price of insurance in the market.

The essential reason why women pay higher insurance premiums than men for disability insurance and a higher price to purchase an annuity, whereas men pay a higher premium for life insurance, is that there is well-established actuarial and statistical evidence relating to sex-based differential risks. These differential risks may reflect biological factors or actions that are correlated with a person's sex. The implication, however, is that the present value of expected costs of providing a woman with an annuity of given value is greater than for a man, while the present value of expected costs of providing a man with a given amount of life cover is greater than for a woman, for the same reason, namely, that on average, women live longer than men. In these circumstances, if men and women are required to buy the same contract, it is arguable that discrimination has been created, not removed.

For example, the United States Supreme Court has argued that using separate mortality tables for men and women in pension compensation plans discriminates against women since they would receive lower annual benefits or pay more for equal benefits than otherwise similar men. But since women outlive men, on average, they receive benefits for a longer period. Since pension compensation is the expected present value of lifetime pension benefits, the use of sex-based mortality tables to set contribution rates removes discrimination by charging males and females the same amount for the same expected present value of future benefits. In this context, McCarthy and Turner (1993) estimate that the unisex policy required by the Supreme Court created sex discrimination equal to 23.4 per cent of pension compensation for males. These calculations, however, presume that insurers will offer men and women the same contract.

Since it is difficult to sustain discrimination in the sense that different groups pay different prices for the same commodity, legislators may need to be properly informed that insurance is not the 'same good' for different risk classes. Consider the recent revision of human-rights legislation in New Zealand. The New Zealand Human Rights Act 1993 amalgamated and revised the Race Relations Act 1971 and the Human Rights Commission Act 1977. Section 48 of the Act effectively maintained previous legislation with respect to insurance in that it provides an exception to s.44 of the Act by permitting insurers to sell annuities, life insurance, and accident insurance policies on different terms and conditions for each sex (and for persons with a disability) as long as the different treatment is based on relevant actuarial or statistical data, or on reputable medical or actuarial advice or opinion. Yet the Act's forerunner, the New Zealand Human Rights Bill 1992, proposed to abandon 
this exception on 1 January 1995. The submission of the Life Offices Association of New Zealand (1993) to the parliamentary select committee dealing with the bill emphasised expected cost differences in supplying different classes of insurance to men and women. This view apparently prevailed.

Nevertheless, some legislators choose to proceed with anti-discrimination policies in spite of sex-based cost differences. One argument is that it is unfair that high-risk groups should face higher insurance premiums, particularly if the higher risk results from bad luck of the draw rather than their actions. Here, legislation is seen to be necessary to compensate for discrimination on the part of nature. Another argument is that although one group may be higher-risk on average, some members of this group may be lower-risk than average, and, if they are not identified, it is inappropriate for them to pay higher premiums. Both of these issues are addressed in following sections. A major conclusion is that legislators against discrimination may be disappointed, since their policies are by no means guaranteed to make high-risk groups better off.

\section{How a Competitive Insurance Market Operates}

To see why anti-discriminators should treat the market as a friend rather than an enemy, consider how a competitive insurance market operates. To keep the analysis simple, and to concentrate on essentials, suppose for the moment that all persons are identical, and have equal earnings in the absence of some form of 'disability'. Each person, however, can suffer a disability that would reduce income by a given amount. The risk of disability is the same for all. Each person is riskaverse, which induces them to buy insurance from risk-neutral insurance firms that pool these various risks with the objective of maximising expected profits. Those customers suffering a disability receive compensatory payments financed from the premiums received from all customers. Insureds voluntarily enter into an agreement to redistribute total premiums contingent upon some of them being disabled. Which persons will be disabled, however, cannot be identified at the time of signing the contract.

If there were no resource costs to operating an insurance company, zero expected profits would imply that total premiums would equal total expected net payouts. It would pay people to insure themselves fully, that is, to purchase just enough insurance so that they would be exactly compensated for the income loss suffered should they become disabled. Define the price of insurance as the premium per dollar of net (of premium) payout in the event of disability. The price of insurance will directly reflect the likelihood that a disability will be suffered. It is assumed that this likelihood is outside the control of a person buying insurance.

The market is efficient. People are doing the best they can, subject to the resource constraints of the situation. No one can be made better off without making someone else worse off. There is no discrimination. Everyone is paying the same premium for insurance which reflects their risk of disability.

Now change the situation slightly. Instead of people being identical in every respect, suppose that the only difference between them (as far as the insurance 
market is concened) is that all women have a higher risk of becoming disabled than do allmen; that is, risks are perfectly categorised. In the absence of regulation, the competitive market outcome is as follows. Both women and men will choose to be fully insured, but men will face a lower premium than women, reflecting their lower risk. Zero expected profits will be made on contracts sold to both men and women, and there will be no cross-subsidisation. To some people, the unwillingness (rather, the inability) of insurers to make men pay higher premiums so as to subsidise the unlucky women is a fault of the market mechanism that anti-discrimination legislation can correct.

The market is still efficient in that both women and men are doing the best they can subject to the resource constraints faced by society. Women can be made better off only by a transfer of resources from men. But what happens when antidiscrimination legislation is enacted? Presumably, legislators expect that if insurance has to be offered under 'the same terms and conditions' to both women and men, insurers will offer everyone the same contract. Now insurers may believe correctly that they cannot now stop women buying the low-priced contract designed for the low-risk men. But this does not imply that insurers will offer women and men the same contract at a price reflecting average risk. Anti-discrimination legislation does not typically appear to require any given insurer either to offer insurance under identical terms to any other insurer, or to prevent any insurer from limiting the amount of insurance offered to anyone. Recognising this opens up wide possibilities and has some surprising results.

\section{A Segregated Insurance Market}

First, suppose that everyone is offered the full-insurance contract that women would buy in an unregulated market. Now let some other insurers offer insurance to everyone at a lower price, specifically, that which reflects male risk. However, the insightful insurer knows that if women as well as men can buy a full-insurance contract at this price, losses will be made on sales of the contract to women. So to prevent women from buying insurance at a price reflecting male risk, insurers must offer a contract that men find attractive compared to that being bought by women, while at the same time not attracting the high-risk women (yet being available to women in order to satisfy the legislation).

The outcome in this case is a segregated insurance market. Women buy the same contract as in an unregulated market, and the legislation makes them no better off. Men buy insurance at the same price as in an unregulated market, but cannot buy the full insurance contract they would otherwise choose. Instead, their insurance purchases are rationed, and they remain underinsured. Men receive only partial income replacement should they suffer a disability, and are worse off than in an unregulated market. If men have dependants, they will presumably also be worse off in this situation. The result of the legislation is pure economic waste.

\footnotetext{
${ }^{1}$ These are examined in detail in Woodfield (1994a).
} 
The irony of this situation is apparent. Legislators have apparently outlawed discrimination against women by requiring that insurers should charge women and men the same price for insurance. But this is not what happens. Some insurers are selling low-priced, partial insurance contracts to men, while others are selling highpriced, full-insurance contracts to women. Both contracts, however, are available to everybody. The legislation has merely disadvantaged the low-risk group, which is said to be adversely selected. No person benefits, and an efficient market has been rendered inefficient by the legislation. An insurance market segregated on these lines meets the letter of the law, if not its spirit.

A similar example is as follows. Suppose that incomes differ systematically by sex, and that insurers can costlessly observe income differences. Then it may be possible for well-paid men to be offered full insurance at low premiums reflecting male risk if no similarly-paid women are available to seek insurance on these terms. Insurers could then refuse cheap insurance to low-paid women on the grounds that they do not earn enough to qualify for the policy designed for high-paid workers (who just 'happen' to be males). The market segregates, but there are no welfare effects for anybody. ${ }^{2}$ The fact that the legislation can be effectively bypassed in these examples says little for it.

\section{Imperfect Categorisation}

The situation is more complicated when risks are imperfectly categorised. For example, suppose that women are more likely, on average, to suffer a disability than are men, yet it is known that a small proportion of men are high-risk types and also that a small proportion of women are low-risk types. Suppose further that each insured person knows their appropriate risk class, but that insurers know only that men are typically lower-risk than women. An insurer observing that a customer is a woman cannot be sure whether she is a high-risk or low-risk type, only that it is more likely that she is high-risk than if she were a man. Sex is correlated with risk, but imperfectly so, and the market is characterised by asymmetric information regarding risks between buyers and sellers.

There are now four groups to consider: low-risk men, low-risk women, highrisk men, and high-risk women. If insurers were as well-informed as their customens regarding their appropriate risk class, two full-insurance contracts would be offered. All low-risk persons would buy the same low-premium full-insurance contract while all high-risk persons would buy the same high-premium full-insurance contract. But with asymmetric information, insurers cannot identify which women are high-risk and which are low-risk, or which men are high-risk and which are lowrisk. They consequently set contracts so that their customers identify their risk class by their purchases.

If it is not possible for a firm to introduce any further profitable contracts, the insurance market will adversely select the low-risk group even in the absence of anti-

${ }^{2}$ Further details of related examples may be found in Woodfield (1994b). 
discrimination policy. The reason is that a full-insurance policy with a price reflecting the probability of a disability for the low-risk group would make losses to insurers, who are unable to ensure that only low-risk persons buy it. Excluding all women from the right to purchase this contract would exclude some low-risk women. Permitting all men to purchase the contract would include some high-risk men buying it, and losses would be made on sales to them. Instead, the market offers two contracts, only one of which would be offered under symmetric information. This is the full-insurance high-premium contract, and is purchased by all highrisk men and high-risk women. The second is a low-premium contract, and is purchased by all low-risk men and low-risk women. But this contract also involves rationing of insurance to low-risk types, in order to appear marginally unattractive to high-risk types. Compared to a full-information situation, low-risk men and low-risk women are worse off, while high-risk men and high-risk women are no better off. The market is inefficient relative to the full-information situation. Notably, the same contracts are offered as when categorisation is perfect and insurers are required to offer insurance under the same terms and conditions to men and women.

Anti-discrimination legislators may find this situation unfair to women on two counts. First, the majority of women will be buying insurance at a higher price than the majority of men because nature has unfairly selected women as the high-risk group. Second, the minority of women who are low-risk types appear to be penalised because insurers cannot identify them as such. In particular, high-risk men will not identify themselves as such since this might result in their losing the opportunity to be pooled with low-risk types. However, a similar argument also holds for highrisk women.

Suppose a firm is selling both of these contracts prior to the enactment of antidiscrimination legislation, and then finds itself having to offer insurance under the same terms and conditions to its customers, regardless of their sex. Recall that it is selling two insurance contracts that have different prices. However, some women and some men will be buying each type of contract. Further, no woman or man is prevented from buying either of the available contracts. The firm may well be able to defend successfully a suit brought against it under anti-discrimination legislation. If, however, an insurer must be observed to be selling insurance to men and women at a unisex price, the market will be segregated between a group of firms selling the full-insurance high-premium contract to high-risk men and high-risk women, and a group of firms offering the rationed, low-premium contract that will be bought by low-risk men and low-risk women. Everyone would buy the same contract as they chose prior to the legislation.

As with the case of perfectly categorised risks, anti-discrimination policy is ineffective in raising the welfare of high-risk types, most of whom, by assumption, are women. When risks are imperfectly categorised, however, the welfare of low-risk types, most of whom are men in this example, is unchanged rather than lowered. The welfare of low-risk women, however, does not increase. With perfect categorisation, anti-discrimination policy makes an efficient insurance market inefficient. With imperfect categorisation, anti-discrimination policy does nothing to improve 
an informationally-constrained inefficient (although otherwise efficient) market. Anti-discrimination policy does not even redistribute in favour of the high-risk group.

Why does the market not offer a pooling insurance contract offered to everyone at the same price? First, as Riley (1979) noted, a pooling contract does not satisfy a requirement that contracts satisfy a self-selection constraint, requiring that the contracts chosen reveal information on whether a person is a high-risk type or a low-risk type. Second, as Rothschild and Stiglitz (1976) demonstrated, if a pooling contract is offered, it is always possible for an insurer to enter the market and offer a profitable contract that will attract low-risk types but not high-risk types.

If anti-discrimination policy is ineffective in obtaining benefits for high-risk groups when risk is correlated with easily observable factors such as sex, age, or race, why not tighten the legislation to prevent its intent from being bypassed? For example, why not outlaw those firms selling low-priced, rationed insurance to lowrisk types? Would not a pooling contract reflecting average risk then be offered? To achieve this, it would also be necessary to outlaw all those alternative rationed contracts carrying a lower price of insurance that would attract low-risk types away from the pooling contract. This runs into a possible conflict with competition policy, which encourages non-predatory price cutting. Further, it denies the market its valuable ability to offer a variety of policies to cater for individual differences in attitudes towards risk (which have been assumed away here). If moral hazard is present, so that the probability of disability could be influenced by actions that are hidden from an insurer, forced pooling of different risk categories could lead to inefficient investment in self-insurance and self-protection since insureds no longer face the appropriate price for market insurance.

In any case, however, as shown by Crocker and Snow $(1985,1986)$, it is possible to do better for high-risk groups than simply forcing insurers to offer uniform contracts. This involves setting a lump-sum tax on a low-risk group, the proceeds of which are used to finance a lump-sum subsidy on a high-risk group. Crocker and Snow show that it is always possible for a low-risk group to overcompensate a highrisk group in order for them to get the benefits of categorisation of risk when categorisation is either costless or at least not too costly, which is surely true for categorisation by sex, age, or race. Two points, however, arise in this context. First, the implementation of a tax/subsidy scheme may be very costly, and would be even more so if there were differences in attitudes towards risk, since different tax and subsidy rates for different people would require computation. Second, the exercise may be largely umecessary if it is accepted that disadvantage in some markets, such as being a high-risk woman, is offset by corresponding advantages in other markets. For example, while longevity appears to be a source of disadvantage for women in the annuities market, it is a source of advantage in the life-insurance market, and is a source of value in its own right, since, other things equal, people typically prefer a longer lifespan to a shorter one. It is not appropriate to focus attention on just one discrimination policy. 


\section{Concluding Remarks}

Anti-discrimination policy that attempts to prevent insurers from categorising risks is generally ill-conceived. It may confuse the source of apparent discrimination, and may even introduce a form of discrimination if low-risk groups are required to subsidise high-risk groups. But the policy may also be effectively evaded by insurers, in which case persons alleged to be suffering discrimination are not made better off, while the rest of society is either worse off or no better off. Policies based on lumpsum taxes and transfers may be preferable, but only in the context of incomedistribution policy in general.

\section{References}

Crocker, K. \& A. Snow (1985), 'A simple tax structure for competitive equilibrium and redistribution in insurance markets with asymmetric information', Southem Economic Journal 51: 1142-50.

(1986), 'The efficiency effects of categorical discrimination in the insurance industry', Journal of Political Economy 94: 321-44.

Life Offices Association of New Zealand (1993), Human Rights Bill: Submission to the Justice and Law Reform Select Committee, Wellington.

McCarthy, D. \& J. Tumer (1993), 'Risk classification and sex discrimination in pension plans', Journal of Risk and Insurance 60: 85-104.

Ríley, J. (1979), ‘Informational equilibrium', Econometrica 47: 331-59.

Rothschild, M. \& J. Stiglitz (1976), 'Equilibrium in competitive insurance markets: an essay on the economics of imperfect information', Quarterly Joumal of Economics 90: 629-49.

Woodfield, A. (1994a), 'Insurance market equilibrium and the welfare costs of gender-neutral insurance pricing under alternative regulatory regimes', University of Canterbury Discussion Paper \# 9401 .

_ (1994b), 'Labour market signalling and the welfare costs of regulated insurance market equilibria under gender-neutral pricing', University of Canterbury Discussion Paper \# 9402.

I would like to thank the referees for their helpful comments on an earlier draft, but take responsibility for what remains. 